\section{Determining whether the symptoms of Female Athletic Triad in Badminton female league athletes and National Team existand the knowledge levels of them on Female Athletic Triad ${ }^{1}$}

\section{Atletik Triad'in belirtilerinin kadın lig ve A Milli Takımındaki Badminton sporcularında görülme durumu ve bu sporcularin Atletik Triad hakkındaki bilgi düzeylerinin belirlenmesi}

\section{Abstract}

In this study it was aimed to determine the knowledge levels of female athletes in badminton players and national team of Badminton on Female Athletic Triad and whether the athletes experience the symptoms of "Female Athletic Triad". The study was carried out voluntarily with the participation of a total number of 34 athletes from Badminton players. 9 of the athletes were from national team and 25 were from Badminton league players. As a measuring tool,"Female Athletic Triad" questionnaire was used in the study. The questionnaire was constructed by Heidi Wengreen She was created this questionnaire in 2004. Consequently, it has been found out in the study that woman athletes in both groups have never heard about "Female Athletic Triad". To the question about calorie intake $\% 25$ of badminton league player answered that they
Özet

$\mathrm{Bu}$ araştırmada, ülkemizdeki kadın lig badmintoncularıyla A milli takım düzeyindeki kadın badmintoncuların Kadın Atletik Triad'ı hakkındaki bilgi düzeyleri ve sporcularımızın Kadın Atletik Triad belirtilerini taşıyıp taşımadıklarının belirlenmesi amaçlanmıştır. Araştırma, 2015 Nisan - Mayıs ayları arasında A Milli takım kadrosunda yer alan 9 Milli Badmintoncuyla 25'i Lisanslı Badminton Lig sporcusu olmak üzere toplam 34 sporcunun gönüllü katılımıyla gerçekleştirilmiştir. Araştırmada veri toplama araçları olarak, Wengreen tarafindan 2014 yilinda oluşturulan genel geçerliliği kontrol edilmiş Female Athletic Triad Anketi kullanılmıştır. Yapılan çalışmada sonuç olarak; her iki gruptaki bayan sporcuların da "Kadın Atletik Triad'ını daha önce duymadıkları belirlenmiştir. Kalori alımıyla ilgili soruda Lig Badmintoncularının \%25'i

\footnotetext{
${ }^{1}$ This study is summarized from a part of Master's Thesis prepared for the Sakarya University, Physical Education and SportsTeaching Programme, the department of Physical Education and Sports

2 M.Sc., Sakarya University, Physical Education and Sports Teaching Programme, The department of Physical Education and Sports, mugesarper@hotmail.com

${ }^{2}$ Assoc. Prof. Dr., School of Physical Education and Sports, Sakarya University, Sakarya/Turkey, herguner@sakarya.edu.tr

4 Assist. Prof. Dr., School of Physical Education and Sports, Sakarya University, Sakarya/Turkey, calbayrak@sakarya.edu.tr
} 
Sarper Kahveci, M., Hergüner, G., \& Albayrak, C. (2016). Atletik Triad'ın belirtilerinin kadın lig ve A Milli Takımındaki Badminton sporcularında görülme durumu ve bu sporcuların Atletik Triad hakkındaki bilgi düzeylerinin belirlenmesi. Journal of Human Sciences, 13(2), 3643-3653. doi:10.14687/ihs.v13i2.3911

couldn't take enough amount of calorie. To the question about stress fracture \%66 of national team players answered "yes" still, when they are asked about their first menarch age. It was found out that league players ranges in 14-15 age group and national team players ranges in 15-16 age group. Lastly when they are asked about their period regularity. National team players reported that their regularity is usually very irregular throughout the year. Based on all this information about "Female athletic triad" it was suggested to give seminers and disseminate these seminars via Youth and Sport Ministry Sport and Eduation Office and sport federations to the players in all branches including badminton players.

Keywords: Female Athletic Triad; Female Badminton Player; National Badminton Team.

(Extended English abstract is at the end of this document) alamıyoruz cevabını vermiștir. Stres kırığıyla karşılaşma sorusuna Milli Badmintoncuların $\% 66$ 's1 evet yanıtını vermiştir. Yine pek çok badmintonucunun ilk menarş yaşı sorulduğunda Lig badmintoncularının genelde 14-15 yaş grubunda, Milli sporcuların ise genelde 15-16 yaş grubunda oldukları saptanmıştır. Son olarak reglilerinin düzenliliği ile ilgili sorulan soruda genellikle Milli Badmintoncuların \%44'ünün adetlerinin y1l içinde çok düzensiz olduğunu belirtmişlerdir. Bütün bu sonuçlardan yola çıarak; öncelikle araştırma sonucunda risk altında bulunan sporcuların Kadın Atletik Triadı hakkında Gençlik ve Spor Bakanlığı Spor Eğitim Dairesi ve spor federasyonlarinin alan uzmanlarından destek alınarak hazırlanacak seminerler aracillğıyla bilgilendirilmesi ve sonrasinda bu seminerlerin badminton dahil olmak üzere her spor branşı için yaygınlaştırılması önerilebilir.

Anahtar Kelimeler: Kadın Atletik Triadı; Kadın Badmintoncular; Badminton.

\section{Giriş}

Kadınların spora katılımları kendilerine saygıyı artıırken takım arkadaşlarıyla da arkadaşlığı geliştiriyor ve böylece kadın sağlı̆̆ı için yararlı etkiler oluşturabiliyor. Ancak biz kadınların spora katılımlarının patlama yapmasıyla birlikte, gelişen kendine mahsus medikal durumların kadınları riske soktuğunun farkındayız. Bunlardan en önemlisi de Kadın Atletik Triad'ıdır(Troy, K. ve ark. 2006).

Atletik Triad üç önemli bileşeni içeren bir sendrom olarak tanımlandı. a) Yeme bozukluğu, b) Amenorrhea, c) Osteoporesis. The American College of Sports Medicine 1997'de bölüm olarak yayınladı ve o zaman bu sendromun önemini desteklemek için daha fazla epidemiyolojik, laboratuvar ve veri incelenmesi gerekti(Dipietro ve Stachenfeld, 2006).

Triad'ın üç bileşeni de tüm psikolojik ve fizyolojik mekanizmalarla ilişkilendirilir. Psikolojik bask1 yoğun antrenmanın sonucunda performansı optimal bir standartta tutmak ve s1k s1k algilanan düşük yağ oranını elde etmeyi sürdürmek için oluşur. Menstural döngünün endokrinolojik kontrolünde düşük enerji alımı kombinasyonu ve psikolojik değişimler tarafindan stres hormonu üretilir. $\mathrm{Bu}$ durum sporcunun amenorrhea(reglinin anormal olarak kesilmesi ya da yokluğu) olmasına sebep olabilir. Amenorrhea hipotalamus ve hipofiz bezinin bozukluğu sonucu östrojen üretiminin azalmasına sebep olur. Bu hormon kemik mineral yoğunluk miktarının sürdürülmesinde etkilidir. Düşük östrojen seviyesi bu yüzden düşük kemik yoğunluğuyla ve osteoporesisin artmasıyla ilişkilidir(Birch, K., 2005).

\section{Yeme Bozukluğu}

Kadın sporcuların, özelliklede dayaklılık sporlarına katılan ya da görünüşe vurgu yapan sporlardaki kadınlar diğer yarışmasız gruplarındakilerden daha fazla yeme bozukluğu riski altında olduğunu gösteren kanıtlar vardır. Örneğin, yeme bozukluğunun yaygınlı̆ı kadın sporcularda \%1562 olmasına rağmen ergenlik çağındaki ve genç kadınlarda \%0.5-3.0'dır(Hinton, PS. ve Beck, NC. 2005). 
Sarper Kahveci, M., Hergüner, G., \& Albayrak, C. (2016). Atletik Triad'ın belirtilerinin kadın lig ve A Milli Takımındaki Badminton sporcularında görülme durumu ve bu sporcuların Atletik Triad hakkındaki bilgi düzeylerinin belirlenmesi. Journal of Human Sciences, 13(2), 3643-3653. doi:10.14687/ihs.v13i2.3911

Sürdürülebilir düșük enerji alımı, yeme bozukluğuyla sağlığı zayıflatabilir ve bazı medikal komplikasyonlara sebep olabilir. Örneğin kardiyovaskuler, endokrin, üriner, iskelatal, gastrointestinal, böbreksel ve merkezi sinir sistemi rahatsılılklanına yol açabilir(Soleimany1, G. ve ark. 2011).

\section{Amenorrhea ve Oligomenore}

Amenore, menstural kanamanın olmaması şeklinde tanımlanır. Üreme çağındaki kadınlarda insidesi $\% 5$ 'dir. Amenore'nin fizyolojik yani normal olduğu durumlar yalnızca pubertal dönem, gebelik, laktasyon ve menapoz'dur. Amenore bir tanı veya hastalık değildir, daha çok üreme sisteminde herhangi bir seviyedeki patalojik oluşumun semptomudur (Burnett, AF. 2001).

Amenorria gibi menstural bozukluklar pek çok faktöre bağlıdır; ırkı içeren, genetik telafi, BMI ve aile geçmişi gibi. Halbuki, literatür Amenore'nin genel nüfus yoğunluğuna göre sporcular arasında daha yaygın olduğunu gösterir. Menstural döngünün her yll 8'den az görülmesi ya da döngü sürecinin 35 günü aşmasına Oligamenore denir(Dadgostar, H. ve ark. 2009).

\section{Egzersiz ve Amenorrhea İlişkisi}

Diyet değişikliği, akut ve kronik egzersizin etkileri, hormon metabolizmasında değişiklik, artan yağ oranı yüzünden, fiziksel ve psikolojik, antrenmanın stresi gibi pek çok neden katkıda bulunabilir ve bireysel farklılıklarda önemli çeşitlilikler olabilir. Genellikle kadının düzenli dayanıklılık antrenmanıyla ilişkisi çalısmaların çoğunda düşük leptin seviyesi ve normal sirkadiyan leptin seviyesinin yokluğu yemek yemeye karşı davranışlarını bozmakta olduğu dosyalanmışır(Rebar, R. 2014).

\section{Osteoporoz ve Kadın Atletik Triad (KAT) İlişkisi}

Osteoporoz hayatın hem kalitesini hem de miktarını düşüren şiddetli bir hastalıktır. Bu hastalık kemik gücünü artırırken kırık riskini yükselten karekterize bir hastalıktır ve yetişkin tepe noktası standart sapması 2.5'un altındayken klinik olarak düşük mineral yoğunluğu teşhisi konur. Bu hastalık ve ölüm oranını arttırır ve dünya çapında yüzlerce insanı etkiler. Her iki cinsten birinde de meydana gelebilirken, özellikle Kafkasya ve Asya kökenli kadınlarda hastalığın görülme sıklı̆g daha fazladır. Hatta Atletik Triad yüzünden kadınlarda osteoporoz riski daha da fazla olabilir(Nguyen, V.H. ve ark. 2014).

\section{Görülme S1klığ1}

Tüm kadın sporcular potansiyel olarak gelişen triad'ın riski altında bulunmaktadır, fakat bu mücadele sporlarında önemli olan vücut yağ oranı düşük olanlar ya da düşük kilolu sporcular belki de triad'ın yüksk riski altında olabilir. Halbuki, diğer bir görüş ile bu sendromun sadece elit sporcularda değil aynı zamanda özel bir branşta karşılaşma ya da antrenman yapmayan ama fiziksel olarak aktif olan ya da sporcu olmayan kadın ve ya kızların da yakalanabileceği idda ediliyor. Ayrıca, kadın ve kızların fiziksel aktiviteleriyle ilişkili olarak hangi farklı derecelerde triadın riski altında oldukları da açıkça belli değildir (Torstveit, MK. ve Borgen, JS. 2004).

\section{Dünya'da ve Türkiye'de Badminton}

İki veya dört kişinin topu yere düşürmeden raketle karşılıklı vuruş esasına dayalı olarak file üzerinde oynadığı olimpik bir spor dalıdır (Salman, 1994).

1934 y1lında Uluslararası Badminton Federasyonu (International Badminton Federation, I.B.F) kurulmuştur (Salman, 1994: s.10). 1978 yllında Çinin öncülüğünde ikinci bir Dünya Badminton Federasyonu (World Badminton Federation, W.B.F.) kurulmuştur (Yorulmazlar, Kepoğlu, 1999: s.4). 1981 yılında yapılan görüşmeler onucu tüm dünya ülkeleri tekrar I.B.F. çatıs1 altında toplanmıslardır. 5 Haziran 1985 yılında I.O.C. Badminton'u 1992 Barcelona Olimpiyatların da madalyalı sporlar arasına almaya karar vermişlerdir (Salman, 1994: s.10). 
Sarper Kahveci, M., Hergüner, G., \& Albayrak, C. (2016). Atletik Triad'ın belirtilerinin kadın lig ve A Milli Takımındaki Badminton sporcularında görülme durumu ve bu sporcuların Atletik Triad hakkındaki bilgi düzeylerinin belirlenmesi. Journal of Human Sciences, 13(2), 3643-3653. doi:10.14687/ihs.v13i2.3911

Türkiye'de Badminton Federasyonu (T.B.F) 31 Mayıs 1991 tarihinde kurulmuştur. Son derece zevkli ve mücadele gerektiren bu spor dalı, kısa geçmişine rağmen sevilmiş, toplumun her kademesinde beğeni kazanmıştır. Türkiye Badminton Federasyonunun, Uluslararası Badminton Federasyonuna yaptığı başvuru sonucunda ülkemiz 3 Kasım 1991 tarihinde 104. Üye sifatıyla tam üyeliğe kabul edilmiştir. T.B.F' nun ilk başkanı İrfan YILDIRIM' dır. 5 Aralık 1993 tarihinde ülkemizde ilk kez yapılan federasyon başkanlı̆̆ seçiminde ise Akın TAŞKENT seçilerek federasyon başkanllğ1 görevini yürütmüştür. Şimdi ise federasyon başkanlığ1 görevini 2 dönemdir Murat ÖZMEKİK yürütmektedir (Yumuk, 2004: s.3).

\section{Materyal ve Yöntem}

Araştırma grubu, Türkiye'deki kadın A Milli takımlarda oynamakta olan badmiton sporcuları ve Badminton Lig sporcularından oluşmaktadır. Katılımcıların 9'u Milli badmintoncu 25'i Lisanslı Badminton Lig sporcusu olmak üzere toplamda 34 gönüllü sporcudan oluşmuştur.

Araştırmada veri toplama aracı olarak Utah State University Öğretim Üyesi Heidi Wengreen tarafindan 2014 yllinda hazırlanan 6 sosyo-demografik soru devaminda da Female Athletik Triad hakkında 26 soru, toplamda 32 sorudan oluşan Female Athletic Triad Anketi kullanılmıstır.

Araştırma, Kadın Atletik Triad'ı taşıma riski olan ya da olmayan tüm bayan sporculara uygulatılmak üzere planlanmıştır. Anket gmail aracilığı ile internet üzerinden tüm sporculara mail yoluyla gönderilmek üzere sanal ortamda hazırlanmıştır. Anket bilgilerinin gizli kalacağı bildirilmiş ve anketin objektif olarak cevaplanabilmesi için sporculardan ad soyad gibi özel bilgiler istenmemiştir. Veri toplama işlemi Mayıs-Aralık 2015 tarihleri arasında yapılmıştır.

Araştırma sonucunda elde edilen veriler SPSS (Statistical Package for Social Sciences) 21.0 paket programında istatistiksel açıdan analiz edilmiştir. İstatiksel analiz aşamasında şu işlemler gerçekleştirilmiştir;

- Öncelikle sporcuların kişisel özelliklerini tanımlayıcı istatistik yaparak yüzde dağılımları çıarılmıstır.

- Sporcuların 32 soruya da toplu olarak verdikleri cevapların \%'lik ortalaması için frekans dağılımları çıkarılmıştır.

- Son olarak badmintoncuların ayrı ayrı her soruya verilen cevaplarının \%'lik ortalaması için yine frekans dağılımlarına bakılmıştır.

\section{Bulgular}

\section{Tablo 1. Sporcuların Yaş Değerleri}

\begin{tabular}{lllll}
\hline \multirow{3}{*}{ YAŞ } & Branşlar & Minimum & Maximum & Ortalama \\
\cline { 2 - 5 } & Badminton & 18 & 24 & 21 \\
& Badminton M & 18 & 23 & 20 \\
\hline
\end{tabular}

Tanımlayıcı istatistik tablosuna bakıldığında spor branşlarına ait yaş ortalamalarında Minimum Maximum ve Ortalama değerlere bakılarak Lig Badmintoncularının Minimum yaş değeri 18 Maksimum yaş değeri 24 ortalama değerleri ise 21 olarak görülmüş̧ür.

Tanımlayıcı istatistik tablosuna bakıldığında Milli takım badmintocularının Minimum yaş değeri 18 Maksimum yaş değeri 23 ortalama değerleri ise 20 olarak görülmüsstür. 
Sarper Kahveci, M., Hergüner, G., \& Albayrak, C. (2016). Atletik Triad'ın belirtilerinin kadın lig ve A Milli Takımındaki Badminton sporcularında görülme durumu ve bu sporcuların Atletik Triad hakkındaki bilgi düzeylerinin belirlenmesi. Journal of Human Sciences, 13(2), 3643-3653. doi:10.14687/jhs.v13i2.3911

Tablo 2. Sporcuların Kilo Ortalamaları

\begin{tabular}{llrrr}
\hline \multirow{3}{*}{ KİLO } & Branşlar & Minimum & \multicolumn{1}{c}{ Maximum } & \multicolumn{2}{c}{ Ortalama } \\
\cline { 2 - 5 } & Badminton & 45 & 70 & 57 \\
& Badminton M & 53 & 74 & 62 \\
\hline
\end{tabular}

Tanımlayıcı istatistik tablosuna bakıldığında badmintonculara ait kilo ortalamalarında Minimum Maximum ve Ortalama değerlere bakılarak Lig Badmintoncularının Minimum kilo değeri 45 Maksimum kilo değeri 70 ortalama değerleri ise 57 olarak görülmüsstür.

Tanımlayıcı istatistik tablosuna bakıldığında Milli takım Badmintoncuların Minimum kilo değeri 53 Maksimum kilo değeri 74 ortalama değerleri ise 62 olarak görülmüştür.

Tablo 3.Sporcuların FAT hakkındaki bilgi düzeyleri

\begin{tabular}{llll}
\hline \multirow{2}{*}{$\begin{array}{l}\text { KAT'1 hiç duydunuz } \\
\text { mu? }\end{array}$} & Branşlar & Evet & Hayır \\
\cline { 2 - 4 } & Badminton & $\% 8(2$ kişi $)$ & $\% 91$ (22 kişi) \\
& Badminton $\mathrm{M}$ & $\% 11(1 \mathrm{kişi})$ & $\% 88$ (8 kişi) \\
\hline
\end{tabular}

Frekans tablosuna bakıldı̆̆ında Kadın Atletik Triad'ını Lig Badmintonsu sporcuların \%8'ının daha önce bu terimi duyduğunu \%91'inin ise daha önce hiç duymadığı görülmektedir.

Frekans tablosuna bakıldığında Kadın Atletik Triad'ını Badminton Milli takım sporcuların \%11'inin daha önce bu terimi duyduğunu \%88'inin ise daha önce hiç duymadığ1 görülmektedir.

Tablo 4. Kalori düzeyleri

\begin{tabular}{llll}
\hline \multirow{2}{*}{$\begin{array}{l}\text { Yeterince kalori } \\
\text { alıyor musunuz? }\end{array}$} & Branşlar & Evet & Hayır \\
\cline { 2 - 4 } & Badminton & $\% 75(18$ kişi $)$ & $\% 25$ (6 kişi) \\
& Badminton M & $\% 88$ (8 kişi) & $\% 11$ (1 kişi) \\
\hline
\end{tabular}

Frekans tablosuna bakıldığında "yeterince kalori alıyor musunuz?" sorusuna Lig Badminton branşındaki sporcuların \%75'inin evet cevabını verdiği \%25'inin ise hayır cevabını verdiği görülmektedir.

Frekans tablosuna bakıldığında "yeterince kalori alıyor musunuz?" sorusuna Badminton Milli takım sporcularının \%88'inin evet cevabını verdiği \%11'inin ise hayır cevabını verdiği görülmektedir.

Tablo 5. Sporcuların kilo korumada üzerlerindeki baskı durumu

\begin{tabular}{llll}
\hline \multirow{2}{*}{$\begin{array}{l}\text { Kilonuzu korumakta baskı } \\
\text { hissediyor musunuz? }\end{array}$} & Branşlar & Evet & Hayır \\
\cline { 2 - 4 } & Badminton & $\% 41$ (10 kişi) & $\% 58$ (14 kişi) \\
& Badminton $\mathrm{M}$ & $\% 33$ (3 kişi) & $\% 66$ (6 kişi) \\
\hline
\end{tabular}

Frekans tablosuna bakıldığında "kilonuzu korumak için baskı hissediyor musunuz?" sorusuna Lig Badminton sporcularının \%41'inin evet cevabını verdiği \%58'inin ise hayır cevabını verdiği görülmektedir.

Frekans tablosuna bakıldığında "kilonuzu korumak için baskı hissediyor musunuz?" sorusuna Badminton Milli takım sporcularının \%33'ünün evet cevabını verdiği \%66'sının ise hayır cevabını verdiği görülmektedir. 
Sarper Kahveci, M., Hergüner, G., \& Albayrak, C. (2016). Atletik Triad'ın belirtilerinin kadın lig ve A Milli Takımındaki Badminton sporcularında görülme durumu ve bu sporcuların Atletik Triad hakkındaki bilgi düzeylerinin belirlenmesi. Journal of Human Sciences, 13(2), 3643-3653. doi:10.14687/ihs.v13i2.3911

\section{Tablo 6. Baskının sebepleri}

\begin{tabular}{|c|c|c|c|c|c|c|}
\hline \multirow{3}{*}{$\begin{array}{l}\text { Evet Dediyseniz } \\
\text { Baskı Kimden } \\
\text { Geliyor? }\end{array}$} & Branşlar & Kendimden & Koçum & Akr. & Ailem & Toplum \\
\hline & Badminton & \%41(10kişi) & & & & $\% 4(1)$ \\
\hline & Badminton $\mathrm{M}$ & \%33(3 kişi) & & & & \\
\hline
\end{tabular}

Frekans tablosuna bakıldığında "Önceki soruya evet dediyseniz. bu baskı nerden geliyor?" sorusuna Lig Badminton branşındaki sporcuların \%41'inin Kendimden cevabını \%4'ü ise toplumdan cevabını verdiği görülmektedir.

Frekans tablosuna bakıldığında "Önceki soruya evet dediyseniz. bu baskı nerden geliyor?" sorusuna Badminton branşındaki Milli takım sporcularının \%33'ünün "Kendimden" cevabını verdiği görülmektedir.

Tablo 7. Yarışma veya antrenmanda stres kırı̆̆1 yaşanma durumu

\begin{tabular}{llll}
\hline Hiç stres kırığı ya & Branşlar & Evet & Hayır \\
\cline { 2 - 4 } da çatlağı & Badminton & $\% 16(4$ kişi) & $\% 83$ (20 kişi) \\
yaşadınız mı? & Badminton M & $\% 66(6$ kişi) & $\% 33$ (3 kişi) \\
\hline
\end{tabular}

Frekans tablosuna bakıldığında "Hiç bir yarışma veya antrenman sonucunda stres kırı̆ğ ya da çatlağı yaşadınız mı?" sorusuna Lig Badminton branşındaki sporcuların \%16'sı Evet \%83'ü ise Hayır yanıtını vermiştir.

Frekans tablosuna bakıldığında "Hiç bir yarışma veya antrenman sonucunda stres kırı̆ğ ya da çatlağı yaşadınız mı?" sorusuna Badminton Milli takım sporcularının \%66'sı Evet \%33'ü ise Hayır yanıtını vermiştir.

\section{Tablo 8. Stres kırı̆̆1 yaşama düzeyleri}

\begin{tabular}{lllllll}
\hline Evet dediyseniz & Branşlar & 1 Kere & 2 Kere & 3 & 4 & 4+... \\
\cline { 2 - 6 } $\begin{array}{l}\text { hayatınız boyunca } \\
\text { kaç tane yaşadınız? }\end{array}$ & Badminton & $\% 12(3 \mathrm{kişi})$ & $\% 4(1 \mathrm{kişi})$ & $\% 4(1)$ & & $\% 4(1)$ \\
\hline
\end{tabular}

Frekans tablosuna bakıldığında "Önceki soruya evet dediyseniz hayatınız boyunca kaç tane yaşadınız?" sorusuna Lig Badminton branşının sporcuların \%12'si 1 kere, \% 4'ü 2 kere, \%4'ü 3 kere $\% 4$ 'ü ise 4'ten fazla yanıtını vermişlerdir.

Frekans tablosuna bakıldığında "Önceki soruya evet dediyseniz hayatınız boyunca kaç tane yaşadınız?" sorusuna Badminton Milli takım sporcularının \%33'ü 1 kere yanıtını vermişlerdir.

Tablo 9. Adet (menarş) dönemi hakkında

\begin{tabular}{lll}
\hline $\begin{array}{l}\text { Hiç adet dönemi } \\
\text { geçirdiniz mi? }\end{array}$ & Evet & Hayır \\
\cline { 2 - 3 } & $\% 94(31$ kişi $)$ & $\% 6(2$ kişi $)$ \\
\hline
\end{tabular}

Frekans tablosuna bakıldığında "Hiç adet dönemi geçirdiniz mi?" sorusuna sporcuların 94'ü Evet, \%6'sı Hayır cevabını vermişlerdir.

Tablo 10. Adet (menarş) döngüsüyle ilgili bilgi düzeyi

\begin{tabular}{lccc}
\hline Adet döneminizle ilgili & Çok doğru & Oldukça doğru & Çok doğru değil \\
\cline { 2 - 4 } $\begin{array}{l}\text { soruları ne kadar doğru } \\
\text { cevaplayacağınızı }\end{array}$ & $\% 45(15$ kişi $)$ & $\% 42(14$ kişi $)$ & $\% 12(4$ kişi $)$ \\
düşünüyorsunuz. & & & \\
\hline
\end{tabular}


Sarper Kahveci, M., Hergüner, G., \& Albayrak, C. (2016). Atletik Triad'ın belirtilerinin kadın lig ve A Milli Takımındaki Badminton sporcularında görülme durumu ve bu sporcuların Atletik Triad hakkındaki bilgi düzeylerinin belirlenmesi. Journal of Human Sciences, 13(2), 3643-3653. doi:10.14687/ihs.v13i2.3911

Frekans tablosuna bakıldığında " Adet döneminizle ilgili sorulanı ne kadar doğru cevaplayacağınızı düşünüyorsunuz." sorusuna sporcuların 45'1 Çok doğru, \%42'si Oldukça doğru, $\% 12$ 'si Çok doğru değil cevabını vermişlerdir.

Tablo 11. İlk adet (menarş) dönemine girme yaş1

\begin{tabular}{llcccccccc}
\hline \multirow{2}{*}{$\begin{array}{l}\text { Illk adet dönemi } \\
\text { yaşadığınızda } \\
\text { kaç }\end{array}$} & Branşlar & $\mathbf{1 0}$ & $\mathbf{1 1}$ & $\mathbf{1 2}$ & $\mathbf{1 3}$ & $\mathbf{1 4}$ & $\mathbf{1 5}$ & $\mathbf{1 6}$ & $\mathbf{1 7}$ \\
\cline { 2 - 10 } yaşındaydınız? & Badminton & & & $\% 16(4)$ & $\% 12(3)$ & $\% 37(9)$ & $\% 33(8)$ & & \\
\hline
\end{tabular}

Frekans tablosuna bakıldığında "illk adet dönemini yaşadığınızda kaç yaşındaydınız?" sorusuna Lig Badminton branşının sporcuları \%16's1 12 yaşında \%12'si 13 yaşında \%37'si 14 yaşında $\% 33$ 'ü ise 15 yaşında yanıtını vermişlerdir.

Frekans tablosuna bakıldığında "İlk adet dönemini yaşadığınızda kaç yaşındaydınız?" sorusuna Badminton Milli takım sporcuları \%11'i 13 yaşında \%66'sı 15 yaşında \%11'i 16 yaşında ise $\% 11$ 'i ise 17 yanıtını vermişlerdir.

Tablo 12. 1 yıl içinde menarş geçirme sıklığ1

\begin{tabular}{|c|c|c|c|c|c|c|c|c|c|c|c|c|}
\hline \multirow{3}{*}{$\begin{array}{l}\text { 1yıl içinde } \\
\text { kaç adet } \\
\text { dönemi } \\
\text { geçirdiniz? }\end{array}$} & Branşlar & 2 & 5 & 7 & 8 & 9 & 10 & 11 & 12 & 13 & 14 & 15 \\
\hline & Badminton & & $\% 4$ & & & & & $\% 12$ & $\% 79$ & & & $\% 4$ \\
\hline & Badminton M & & & $\% 11$ & $\% 11$ & $\% 11$ & & & $\% 55$ & & & \\
\hline
\end{tabular}

Frekans tablosuna bakıldığında "1 yıl içinde kaç adet dönemi geçirdiniz?" sorusuna Lig Badminton branşının sporcuları \%4'ü 5 kere \%12'si 11 kere \%79'u ise 12 kere \%4'ü ise 15 kere yanıtını vermişlerdir.

Milli takım sporcuları \%11'i 7 kere \%11'i 8 kere \%11'i ise 9 kere \%55'i ise 12 kere yanıtını vermişlerdir.

Tablo 13. Adet (menarş) düzeni hakkında

\begin{tabular}{llccc}
\hline Adet döneminizin & Branşlar & Çok düzenli & Biraz düzensiz & Çok düzensiz \\
\cline { 2 - 5 } düzenliliğini tarif eder & Badminton & $\% 70$ & $\% 25$ & $\% 4$ \\
misiniz? & Badminton $\mathrm{M}$ & $\% 33$ & $\% 22$ & $\% 44$ \\
\hline
\end{tabular}

Frekans tablosuna bakıldığında "Adet döneminizin düzenliliğini tarif eder misiniz?" sorusuna Lig Badminton branşının sporcuları \%70'i Çok düzenli \%25'i Biraz düzensiz \%4'ü ise Çok düzensiz yanıtını vermişlerdir.

Frekans tablosuna bakıldığında "Adet döneminizin düzenliliğini tarif eder misiniz?" sorusuna Badminton branşının sporcuları \%33'ü Çok düzenli \%22'si Biraz düzensiz \%44'ü ise Çok düzensiz yanıtını vermişlerdir.

\section{Tartışma Sonuç}

Literatür tarandığında Brown, Wengreen ve Beals tarafindan 2014 yılında liseli sporcular ve koçları üzerinde yapılan araştırmalarda sporcuların ve koçların kadın atletik triadı hakkında yeterli bilgileri olmadığına ulaşılmışıtır. Yapılan araştırmaya göre de Lig sporcuların \%91'inin ve Milli Takım Badmintocularının da \%88 nin atletik triadı daha önce hiç duymamış oldukları saptanmıştır. Böylece sonuçlar literatürle örtüşmüştür.

Yeterince kalori alıyor musunuz sorusuna verilen cevaplara bakıldığında özellikle Lig Badmintoncularının \%25'i hayır cevabını verdikleri görülmüştür. Sleight ve arkadaşları 2015'te yapmış oldukları çalışmada yeme bozukluğunun teşhisinin önemine değinmiştir ve genellikle yeme 
Sarper Kahveci, M., Hergüner, G., \& Albayrak, C. (2016). Atletik Triad'ın belirtilerinin kadın lig ve A Milli Takımındaki Badminton sporcularında görülme durumu ve bu sporcuların Atletik Triad hakkındaki bilgi düzeylerinin belirlenmesi. Journal of Human Sciences, 13(2), 3643-3653. doi:10.14687/ihs.v13i2.3911

bozukluğu olan atletlerin bunu bir utanç kaynağı olarak görüp saklamalarının da klinik teşhis koyma bakımından şartları zorlaştırdığını özellikle vurgulamıştır. Bu kaynağa dayanarak verilen cevapların ciddi boyutlarda olmasıyla birlikte atletlerin klinik kontrollerinin yapılması gerektiği uygun olacağ1 düşünülmektedir.

Kilonuzu korumak için baskı hissediyor musunuz sorusuna her 2 grubunda ciddi oranda evet dediğini görülmüştür. Literatüre bakıldığında ise Coelho ve arkadaşları 2014'te yaptıkları çalışmada en çok risk altında bulunan branşların genellikle vücut yağ yüzdesinin önemli olduğu branşlar olduğunu öne sürmüşlerdir. Sporcuların kadın atletik triadına yakalanmaması için en önemli basamağın da yeme bozukluğunu teşhis etmek ve önlemek olduğunu savunmuşlardır.

Yukarıdaki kilonuzu korumak için baskı hissediyor musunuz sorusuna her 2 grupta \%80'nin üzerinde evet olarak cevap vermiştir ve sporcular bu baskının kendilerinden geldiğini söyledikleri görülmüştür. Ancak literatür tarandığında bu durumu destekler bir kaynağa ulaşılamamıştır.

Daha önce hiç stres kırı̆̆ yaşadınız mı sorusuna en çok Milli Badmintoncuların evet dediği ortaya çıkmıştır. Yapılan literatür taramalarında ise Warden ve arkadaşları tarafindan 2014 yılında yapılan çalışmada uzun mesafeci atletlerin sadece bu hastalığa yakalanma oranının değil bir de bu hastalığa yeniden yakalanmaya da yatkın olduklarına değinilmiştir. Ancak yapılan literatür taramalarında stres kırı̆ı̆yla ilgili badminton branşında daha önce yapilmış bir araştırmaya rastlanılmamıştır.

İlk adet dönemini ne zaman geçirdiniz sorusuna Lig badmintoncularının geneli 14-15 yaş grubunda Milli Badmintoncularda ise 15-16 yaş grubunda başladıkları hatta 1 sporcunun da 17 yaşında ilk adet (menarş) periyoduna başladığı öğrenilmiştir. Literatüre bakıldığında ise Dadgostar ve arkadaşlarının pek çok elit branşı karşılaştırdığı 2009'daki çalışmasında, çalışmaya katılan 788 sporcunun geç adet (menarş) yaşı problemi olduğu görülmüştür.

Bir yılda toplam kaç kez adet gördünüz sorusuna Lig Badmintoncularının genelinin normal kabul edilen aralıkta olduğu görülmüştür. Milli Badmintoncular da ise sporcuların \%33'ü 9 ve daha az kere cevabını verdikleri görülmüştür. Literatüre bakıldığında Dadgostar ve arkadaşları tarafından 2009 yılında yapılan çalışmada 34 spor federasyonunun katılımıla gerçekleştirilen çalışmada 20 yaşın altındaki sporcuların oligamenori ve amenori bakımından risk altında olduklarına rastlanmış. Özellikle de ağırlık ve dayanıklılık sporlarında amenori ve oligamenori görülme riski olduğu ortaya çıkmıştır. Badminton branşı da içinde dayanıklılık barındırdığ için literatürle örtüşmüştür.

Adet düzeninizi nasıl tanımlarsınız sorusuna ise Lig Badmintoncularının \%4'ü Milli Badmintoncuların ise \%44'ü düzensiz ve çok düzensiz yanıtlarını vermişlerdir. Okunan çalışmalar ve kaynaklar 1şığında ağır yüklenmelerin yapıldığı branşlarda sporcuların adet (menarş) döngüsünü kaybettiği veya düzensizleştiği görülmüştür. Bu yüzden bu branşlardaki sporcuların oligamenori olmaları yaptıkları ağır antrenmanlarla ilişkilendirilebilir.

Her 2 grupta bulunan sporcular Kadın Atletik Triad'ını hemen hemen hiç duymamış olduğu görülmektedir.

"Yeterince kalori alıyor musunuz?" sorusuna sporcuların geneli alabiliyoruz yanıtını vermiştir.

Kilo korumak için baskı hissediyor musunuz? sorusuna Lig badmintoncuları \%41'i Milli Badmintoncuların \%33'ü "Evet" cevabını vermiştir. Aynı sporcular bu baskının en çok kendilerinden geldiğini söylemiştir.

Stres kırıklarını görülme oranı Milli badmintoncularda ve Lig badmintoncularında da ciddi kır1kla karşılaşma sıklı̆ğ görülmüştür.

İlk adet (menarş) yaşı Lig Badmintoncularında 9 sporcu 14 yaşında - 8 sporcu ise 15 yaşında, M. Badmintoncularda ise 15 yaşında 6 sporcu - 16 yaşında 1 sporcu - 17 yaşında ise 1 sporcunun olduğu görülmüştür. Genel ortalamaya bakıldığında en geç adet (menarş) yaşı Milli Badmintoncularda kaydedilmiştir.

Yılda kaç kez regli oluyorsunuz sorusuna Lig Badmintoncuları normal aralıkta cevabını verirken Milli Badmintoncuları 9 ve daha az cevabını vermiştir. 
Sarper Kahveci, M., Hergüner, G., \& Albayrak, C. (2016). Atletik Triad'ın belirtilerinin kadın lig ve A Milli Takımındaki Badminton sporcularında görülme durumu ve bu sporcuların Atletik Triad hakkındaki bilgi düzeylerinin belirlenmesi. Journal of Human Sciences, 13(2), 3643-3653. doi:10.14687/ihs.v13i2.3911

Adetlerinin düzenliliğiyleyle ilgili sorulan soruda genellikle Milli Badmintoncular reglilerinin y1l içinde çok düzensiz olduğunu belirtmişlerdir.

\section{Öneriler}

Öncelikle araștırma sonucunda risk altında bulunan sporcuların Kadın Atletik Triadı hakkında Gençlik ve Spor Bakanlığı Spor Eğitim Dairesinden ve spor federasyonlarının alan uzmanlarından destek alınarak hazırlanacak seminerler aracilı̆ıyla bilgilendirilmesi ve sonrasında bu seminerlerin her branş için yaygınlaştırılması önerilebilir.

Ayrıca sporcuların katıldığı milli takım kamplarında Female Athletic Triad'ıyla ilgili sporculara düzenli olarak milli takım sağlık ekibi tarafindan da bilgi verilebilir, kontrolleri yapılabilir ve artık Türkiye'de de laboratuvar çalışmalarının başlatılması önerilebilir.

Bunlara ek olarak, her branştaki antrenörlerin de Kadın Atletik Triadı hakkındaki bilgi düzeylerine ilişkin araştırmalar yapillp kendilerine konuyla ilgili düzenli ve kapsamlı seminer programlarının uygulanması önerilebilir.

\section{Kaynakça}

Birch, K. (2005). "Female Athlete Triad" Canadian Family Physician. vol:51, p:1344.

Brown,K.N. Wengreen, H.J and Beals, K.A. (2014). "Knowledge of the female athlete triad, and prevelance of triad risk factors among female high school athletes and their coaches". Journal of Pediatrist Adolecent Gynecology 27(5): p278-82. DOİ:10.1016/j.jpag2013.11.014.

Coelho, G.M. Gomes, A.L Riberio B.G. and Soares Ede, A. (2014). "Prevention of eating disorders in female athletes". Journal of Sports Medicine. 12;5:105-13. DOİ: 10.2147/OAJSM.S36528.

Dadgostar, H. Razi, M. Aleyasin, A. Alenabi, T. and Dahaghin, S. (2009). "The relation between athletic sports and prevalence of amenorrhea and oligomenorrhea in Iranian female athletes" Tehran University Iran. Sport Medicine, Arthroscophy, rehabilitation, theraphy \& technology 1 (1), 1.

Dipietro, L. and Stachenfeld, N.S. (2006). "The myth of the female athlete triad" Br Journal of Sports Medicine Yale University. 40, p:490

Hinton, P.S. and Beck, N.C. (2005). "Nutrient intakes of men and women collegiate athletes with disordered eating". Journal of Sports Science and Medicine 4, 253-262 University of MissouriColombia, America.

Nguyen, V.H.,Wang, Z. and Okamura, S.M. (2014). "Osteoporosis Health Beliefs of Women with Increased Risk of the Female Athlete Triad" Hindawi Publisbing Corporation Journal of Osteoporosis Vol 2014, Article ID 676304, 5 pages http://dx.doi.org/10.1155/2014/676304

Rebar, R. (2014). "Evaluation of Amenorrhea, Anovulation, and Abnormal Bleeding" Executive Director of the American Society for Reproductive Medicine in Birmingham, Alabama ABD (Pubmed).

Salman, M.ve Salman, S. (1994). "Badminton Temel Teknikleri ve Ögretimi” 1. Bask1, Ankara: Onay Ajans.

Sleight, A.J. Erickson, C.D. Tierney, D.K. Houston, M.N. and Welch, C.E. (2015). "The diagnostic accuracy of screening tools to detect eating disorders among female athletes: A critically appraised topic. Journal of Sport Rehabilition PMID:26457461

Soleimany, G., Dadgostar, H., Lotfian, S., Lakeh M.M., Dadgostar, E. and Movaseghi, S. (2011). "Bone Mineral Changes and Cardiovascular Effects among Female Athletes with Chronic Menstrual Dysfunction" Asian Journal of Sports Medicine. Vol3, (1) 53-59

Torstveit , M.K. and Borgen, J.S. (2004). "Risk of Female Athletic Triad". The Norwegian University of Sport and Physical Education, Oslo, Norway: The Norwegian Olympic Training Centre(Pubmed).

Torstveit, M.K. and Borgen, J.S. (2007). "The female football player, disordered eating, menstrual function and bone health". Bri Journal of Sports Medicine 41, i68-i72. doi: 10.1136/bjsm.2007.038018 
Sarper Kahveci, M., Hergüner, G., \& Albayrak, C. (2016). Atletik Triad'ın belirtilerinin kadın lig ve A Milli Takımındaki Badminton sporcularında görülme durumu ve bu sporcuların Atletik Triad hakkındaki bilgi düzeylerinin belirlenmesi. Journal of Human Sciences, 13(2), 3643-3653. doi:10.14687/ihs.v13i2.3911

Troy, K. Hoch, A.Z. and Stavrakos, J.E. (2006)."Awareness and comfort in treating the female athletic triad: Are we failing our athletes?" Wisconsin Medical Journal. Vol 105, No 7, p:21.

Warden,S.J. Davis, I.S. and Fredericson, M. (2014). "Management and prevention of bone stress injures in long-distance runners" Journal of Orthphedy Sports Physist Ther. 44(10):749-65. DOİ:10.2519/jospt.2014.5334

Yorulmazlar, M.M. ve Kepoğlu, A. (1999). “Badminton Ders Notlar” İstanbul: Marmara Üniversitesi Beden Eğitimi ve Spor Yüksek Okulu.

Yumuk, S. (2004). “Badminton” Lale Matbaası,Eskişehir.

\section{Extended English Abstract}

Sports paticipation boosts self esteem, fosters friendships with teammates, and can have dramatic beneficial repercussions for women's health. We have also realized from this explosion in sports paticipation that women are at risk for developing unique medical conditions the most serious of which is the Female Athlete Triad(Troy, K. ve ark. 2006).

The female athlete triad is defined as a syndrome consisting of three necessarry components 1-Disordered eating 2-Amenorrhea 3-Osteoporosis and ostepenia. The American College of Sports Medicine (ACSM) published a position stand in 1997 and at the time indicated a strong need for more epidemiological, laboratory and clinical data to support the importance of this syndrome. (Dipietro ve Stachenfeld, 2006).

The three corners of the Female Athlete Triad are related through psychological and physiologic mechanisms. Psychological pressure to perform to an optimal standard - and often a perceived requirement to maintain a low body mass- result in intensive training. This, combined with low energy intake and stress hormones produced by psychological changes in the endocrinologic control of the menstural cycle, can cause athletes to become amenorrheic (absenced or abnormal cessation of menses). Amenorrhea caused by dysfunction of the hypothalamus and pituitary gland results in decreased production of estrogen. This hormone is instrumental in maintaining adequate bone mineral density (BMD). Low estrogen levels are thus associated (Birch, K., 2005).

It has been stated that all female athletes are potentially at risk of developing the triad, but the athletes with low fat levels or low body weight competing in combat sports can be considered under the increased risk of the triad. However, a position statement claims that this syndrome occurs not only in elite athletes but also in non athletes and in physically active girls and women who are not training or competing in a specific sport. It is unclear, however, to what extend girls and woman engaged in physical activity at different levels are at risk of the triad(Torstveit, MK. ve Borgen, JS. 2004).

In this study it was aimed to determine the knowledge levels of female athletes in badminton players and national team of Badminton on Female Athletic Triad and whether the athletes experience the symptoms of "Female Athletic Triad". The study was carried out voluntarily with the participation of a total number of 34 athletes from Badminton players. 9 of the athletes were from national team ( 1 were from choosed up in Rio Oliympic Games group) and 25 were from Badminton league players. As a measuring tool, "Female Athletic Triad” questionnaire was used in the study. The questionnaire was constructed by Heidi Wengreen who is from the academic staffs of Utah University. She was created this questionnaire in 2004. This survey has been occured by 32 questions. (6 questions are socio-demographic. 26 questions are about Female Athletic Triad) By using IBM spss statistic program as method, statistics and frequency tables have been obtained respectively. Scientific studies were identified via data bases of PubMed. A total of 60 articles met the inclusion criteria. 
When we check the findings, it has been found out in the study that woman athletes in both groups have never heard about "Female Athletic Triad". When we check the tables, the average of age is 20 for national badminton players and 21 for league badminton players. Regarding the average of weight for national badminton players is 62 kilograms and for league badminton players is 57 kilograms. To the question about calorie intake $\% 25$ of badminton league player answered that they couldn't take enough amount of calorie. To the question about pressure of ideal weight $\% 41$ in league badminton players \%33 in national badminton players said "yes i feel pressure". To the other question about reason of pressure \%41 in league badminton players $\% 33$ in national badminton players said "from myself" To the question about stress fracture $\% 66$ of national team players answered "yes" still, when they are asked about their first menarch age. It was found out that league players ranges in 14-15 age group and national team players ranges in 15-16 age group. Lastly when they are asked about their period regularity \%70 regular, $\% 25$ a little irregular and \%4 irregular in league badminton player, \%33 regular, \%22 a little irregular and \%44 irregular in national badminton players. National team players reported that their regularity is usually very irregular throughout the year. Thus, all results matched up with literature.

Consequently, based on all this information about "Female athletic triad" it was suggested to give seminers via Youth and Sport Ministry Sport and Eduation Office and sport federations to the players in all branches, especially to all Badminton players.

In addition, athletes can be given information about female athletic triad in national team camps attended by national players by medical team, they can be checked and launching labratory studies in Turkey can also be recommended. Apart from these, investigations on knowledge level of trainers about female athletic triad in every branch can be carried out and they can be offered to arrange seminar programs about this topic regularly and extensively. 